\title{
Understanding Electric Bikers' Red-Light Running Behavior: Predictive Utility of Theory of Planned Behavior vs Prototype Willingness Model
}

\author{
Tianpei Tang $\mathbb{D}^{1,2,3}$ Hua Wang $\mathbb{D}^{1},{ }^{3}$ Xizhao Zhou, ${ }^{1}$ and Hao Gong ${ }^{4}$ \\ ${ }^{1}$ Business School, University of Shanghai for Science and Technology, Shanghai 200093, China \\ ${ }^{2}$ School of Transportation and Civil Engineering, Nantong University, Nantong 226019, China \\ ${ }^{3}$ Department of Civil and Environmental Engineering, National University of Singapore, Singapore 117576 \\ ${ }^{4}$ Landmark (Shanghai) Vision Technology Co., Ltd., Shanghai 200233, China
}

Correspondence should be addressed to Hua Wang; hwang191901@gmail.com

Received 14 December 2019; Accepted 18 January 2020; Published 17 February 2020

Guest Editor: Feng Chen

Copyright (C) 2020 Tianpei Tang et al. This is an open access article distributed under the Creative Commons Attribution License, which permits unrestricted use, distribution, and reproduction in any medium, provided the original work is properly cited.

To date, electric bikers' (e-bikers') red-light running (RLR) behavior is often viewed as one of the main contributors to e-bikerelated accidents, especially for traffic scenarios with high e-bike ridership. In this paper, we aim to understand e-bikers' RLR behavior based on structural equation modeling. Specifically, the predictive utility of the theory of planned behavior (TPB), prototype willingness model (PWM), and their combined form, TPB-PWM model, is used to analyze e-bikers' RLR behavior, and a comparison analysis is made. The analyses of the three modeling approaches are based on the survey data collected from two online questionnaires, where more than 1,035 participant-completed questionnaires are received. The main findings in this paper are as follows: (i) Both PWM and TPB-PWM models could work better in characterizing e-bikers' RLR behavior than the TPB model. The former two models explain more than $80 \%$ ( $81.3 \%$ and $81.4 \%$, respectively) of the variance in e-bikers' RLR behavior, which is remarkably higher than that of the TPB model (only 74.3\%). (ii) It is also revealed that RLR willingness contributes more on influencing the RLR behavior than RLR intention, which implies that such behavior is dominated by social reactive decisionmaking rather than the reasoned one. (iii) Among the examined psychological factors, attitude, perceived behavioral control, past behavior, prototype perceptions (favorability and similarity), RLR intention, and RLR willingness were the crucial predictors of e-bikers' RLR behavior. Our findings also support designing of more effective behavior-change interventions to better target e-bikers' RLR behavior by considering the influence of the identified psychological factors.

\section{Introduction}

In recent decades, as a green, cost-effective, and easy-tocarry transport means, electric bikes (e-bikes) have been adopted and promoted in an increasing number of countries such as Switzerland, Norway, the Netherlands, and China [1-4]. However, the use of e-bikes has been causing increasing e-bike-involved traffic accidents $[1,5,6]$. For example, in China, around 56,200 traffic accidents were caused by e-bikers, resulting in 8,431 fatalities, 63,400 injuries, and direct property losses of 111 million-yuan (equivalent to 16.42 million dollars based on the 2017 average closing exchange rate) between 2013 and 2017 [7]. According to the statistics of accidents related to two-wheeled vehicles (e.g., e-bikes, regular bicycles, and e-scooters) in typical Chinese cities (including Beijing, Changchun, Ningbo, Foshan, and Weihai), e-bike-involved accidents accounted for $34.8 \%$ of the total accidents from July 2011 to June 2016; of the e-bikeinvolved accidents, the proportions of minor injuries, serious injuries, and fatalities to e-bikers were $70.0 \%, 12.6 \%$, and $10.6 \%$, respectively [8]. Some studies reported that the speed and weight of e-bikes were both higher than those of regular bicycles, thereby leading to more injuries and fatalities [9]. In addition, previous findings showed that traffic violating behaviors, especially red-light running (RLR) behavior at signalized intersections, partially contributed to e-bikers-related 
accidents and fatalities [10-16]. Thus, studies on e-bikers' RLR behavior are needed, especially for countries with high e-bike ownership and e-bike-involved accidents.

Previous studies mainly focused on the influence of the demographics and traffic environment on e-bikers' RLR behavior. Moreover, in the studies of psychological factors associated with violating behavior, e-biker-related studies are less than the pedestrian-related and driver-related studies. A recent study has employed a social cognitive theory, the theory of planned behavior (TPB), to recognize the psychological determinants of e-bikers' intention to violate a red light [17]. Nevertheless, some evidence presented that the utility of the TPB framework is insufficient in predicting the unconscious risk-taking behaviors [18-20], while the prototype willingness model (PWM) might be a superior social cognitive theory in predicting such behaviors than the TPB framework [21]. Herein, the main goal of our work is to investigate the predictive utility of TPB, PWM, and their combined form, TPB-PWM, in e-bikers' RLR behavior and explore the psychological mechanism behind this behavior.

\subsection{E-Bikers' RLR Behavior. So far, most existing evidence} has revolved around the red-light infringement behavior of cyclists. Specifically, investigations have been performed on the influence of demographics [11-15], psychological factors [11-13], and other risk behaviors (e.g., unhelmeted riding, carrying passengers, using a phone, and listening to music) $[14,16,22,23]$ on cyclists' RLR behavior. However, due to the differences in weight, speed, and acceleration of e-bikes and regular bicycles, there are some discrepancies in the riders' psychology. Some studies discovered that e-bikers have a stronger intention to violate a red light than regular cyclists [13, 24-28]. Among these studies, Yang et al. [27] proposed that the prominent contributors to RLR behavior of cyclists and e-bikers were individual features (i.e., gender and rider type), psychological factors (i.e., conformity tendency), and traffic factors (i.e., waiting position and traffic volume). Investigations have also been performed on the impact of infrastructure conditions on the RLR behavior of cyclists and e-bikers, such as sunshades [26], carriageway, and intersection types [28]. However, apart from the above studies, much less literature has been published specifically on e-bikers' RLR behavior. Recent research conducted by Yang et al. [17] identified the psychological factors (i.e., attitude, perceived behavioral control, moral norm, and selfidentify) which significantly influenced the e-bikers' RLR intention based on the TPB framework. However, their study focused on e-bikers' RLR intention, but not on their behavior. Also, it is relatively undesirable to employ the extended TPB framework they proposed to predict e-bikers' RLR intention. Thus, other more efficient models were applied to obtain an in-depth investigation of e-bikers' RLR intention and behavior in our study.

\subsection{Theoretical Framework}

1.2.1. TPB Framework. TPB has been the most prevalent framework used to identify the social cognitive constructs that influence traffic violations of drivers, pedestrians, and e-bikers. In reviews of drivers' violations, the TPB framework has successfully explained the violation intentions, including high-speeding [29, 30], drink-driving [31-33], mobile phone use while driving $[34,35]$, and seatbelt nonuse $[36,37]$. In terms of pedestrians' violations, the TPB framework has been employed to understand various pedestrian behavior intentions, such as walking while intoxicated [38], red-light infringement [39, 40], and distracted crossing [41]. In addition to drivers' and pedestrians' violations, Yang et al. [17] also determined the utility of the TPB framework in explaining e-bikers' RLR intention.

As mentioned above, TPB has been supported as a framework for explaining various traffic violations. Nevertheless, it is still unclear whether these behaviors are totally decided by volition. Sheeran et al. [18] pointed out that the TPB framework ignores the spontaneous or heuristic processes, and its hypothesis that a particular behavior is reasoned and premeditated could not match real situations. Also, some studies indicated that the utility of the TPB framework is insufficient in predicting the unconscious risktaking behaviors $[19,20]$. For example, even though e-bikers have a negative attitude towards e-bikers' RLR behavior, they might also have the willingness to violate a red light when there is a traversable space-time gap in the motor vehicle traffic flows.

In this investigation, an extension of the TPB framework (Figure 1) was applied. According to Ajzen's studies [42, 43], RLR intention (RI) reflects an e-biker's readiness to violate a red light. Attitude (AT) refers to an e-biker's positive/favorable or negative/unfavorable perception of RLR behavior. Subjective norm (SN) represents an e-biker's perceived view of whether social referents (e.g., family members and friends) approve or disapprove of RLR behavior. Perceived behavioral control (PBC) reflects an e-biker's perceived view of their ability to violate a red light. In light of previous studies, past behavior was also incorporated into the original TPB framework [29, 44, 45]. Past behavior (PB) represents an e-biker's violating behavior or illegal riding habits in the past and can indicate his/her habit strength $[43,44]$. A range of previous research studies has discussed the explanatory power of the extension of the TPB framework with the addition of past behavior, suggesting that past behavior emerged as a key contributor to behavioral intentions and behaviors in particular correlation with perceived behavioral control $[19,29,43,44]$. In the present model framework, attitude, subjective norm, perceived behavioral control, and past behavior have direct effects on RLR intention and indirect effects on RLR behavior via RLR intention. Also, perceived behavioral control directly influences RLR intention and behavior while indirectly influences RLR intention and behavior through past behavior.

1.2.2. PWM Framework. In fact, e-bikers' crossing behavior is a spontaneous risk-taking behavior that generally requires reactive decisions on how to act in response to changing traffic environmental demands (e.g., traffic signals, traffic volume, and other e-bikers' crossing behaviors) at signalized 


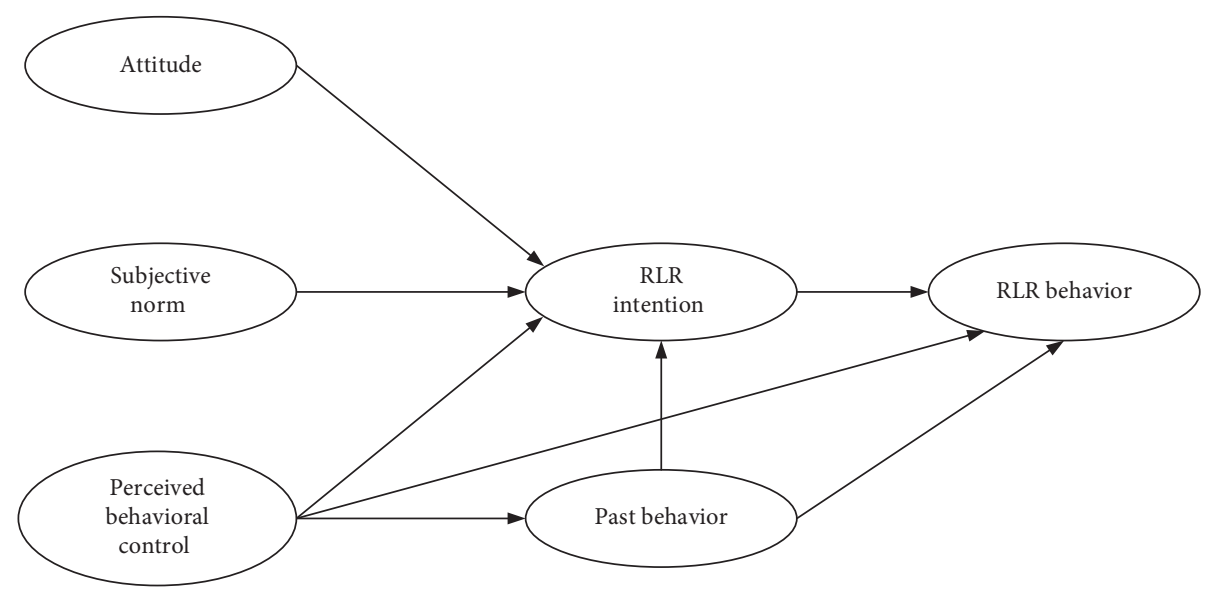

Figure 1: An extension of the TPB framework.

intersections. Thus, other decision-making models might be considered in governing RLR behavior. The PWM framework, which focuses on both social reactive decision-making and reasoned one, might contribute to a better understanding of RLR behavior than TPB framework, which is concentrated on reasoned decision-making only. The PWM framework has been successfully applied in examinations of drivers' and pedestrians' violations, such as drink-driving [46], high-speeding [47, 48], texting while driving [48], and pedestrians' violations [21]. As far as we are concerned, no previous research studies have employed the PWM framework in the study on e-bikers' violations. In this work, the PWM framework was adapted from the study of Gibbons et al. [49] (Figure 2). Among the PWM-based variables, prototype perceptions refer to the images of e-bikers (e.g., age and gender) who engage in RLR behavior, consisting of prototype similarity (PS) and prototype favorability (PF) $[21,49]$. RLR willingness (RW) denotes the e-biker's willingness to violate a red light when such an opportunity is provided $[21,49]$. In the reasoned decision-making pathway, attitude, subjective norm, and past behavior exert direct effects on RLR intention and indirect effects on RLR behavior via RLR intention, while past behavior directly influences RLR behavior. In the social reactive decisionmaking pathway, attitude, subjective norm, prototype similarity, prototype favorability, and past behavior have direct effects on RLR willingness, and RLR willingness directly affects RLR intention and behavior.

1.2.3. Integrating TPB and PWM Frameworks. A few studies have applied the integrative model which incorporates TPB and PWM frameworks (hereafter, referred to as "TPBPWM") to investigate a particular behavior in other domains, such as health-protective/risk behavior [50] and organ donation communication [51]. In recent research, Demir et al. [21] compared the utility of TPB, PWM, and TPB-PWM frameworks in explaining the pedestrians' violations, among which PWM and TPB-PWM frameworks had a better predictive power than TPB framework. In light of the original PWM proposed by Gibbons et al. [49], the past behavior was also a crucial predictor and could improve the PWM's performance. However, the past behavior was not included in Demir et al.'s [21] study, which might have negatively influenced the representativeness of the analysis results. Thus, past behavior was incorporated into three decision-making frameworks in this work. The TPB-PWM framework in this study refers to an extended PWM with the addition of perceived behavioral control, which has a direct effect on RLR intention and behavior (Figure 3).

1.3. Paper Position and Contribution. Little empirical evidence has been reported to support the utility of TPB and PWM frameworks in understanding e-bikers' RLR behavior. In this study, we compared the utility of TPB, PWM, and TPB-PWM frameworks in understanding such behavior, by using the TPB framework as a baseline comparator. This study aimed to test our hypothesis of e-bikers' RLR behavior as being more social reactive (using the PWM/TPB-PWM framework) rather than rational (using the TPB framework). Another aim of this work was to investigate the social cognitive determinants that influence e-bikers' RLR behavior.

\section{Methods}

2.1. Procedures. An experiment was designed using selfreported questionnaires. In the survey, participants who often used e-bikes (on average at least once a day) were asked to answer a wide range of questions related to each variable of the proposed model frameworks in a hypothetical situation. The situation assumed was described as follows: "You are riding an e-bike to work/school or somewhere on time. When you reach a signalized intersection, the traffic light turns red. In this situation, please answer the following questions."

Before the formal survey in this study, we performed a pilot survey among a small total number of 50 participants using online questionnaires. The purpose of this pilot survey was to ensure that the questionnaire items were easy to understand. Also, the pilot survey was helpful to evaluate the completion time of the survey. Cronbach's $\alpha$ correlation analysis and principal component analysis (PCA) were 


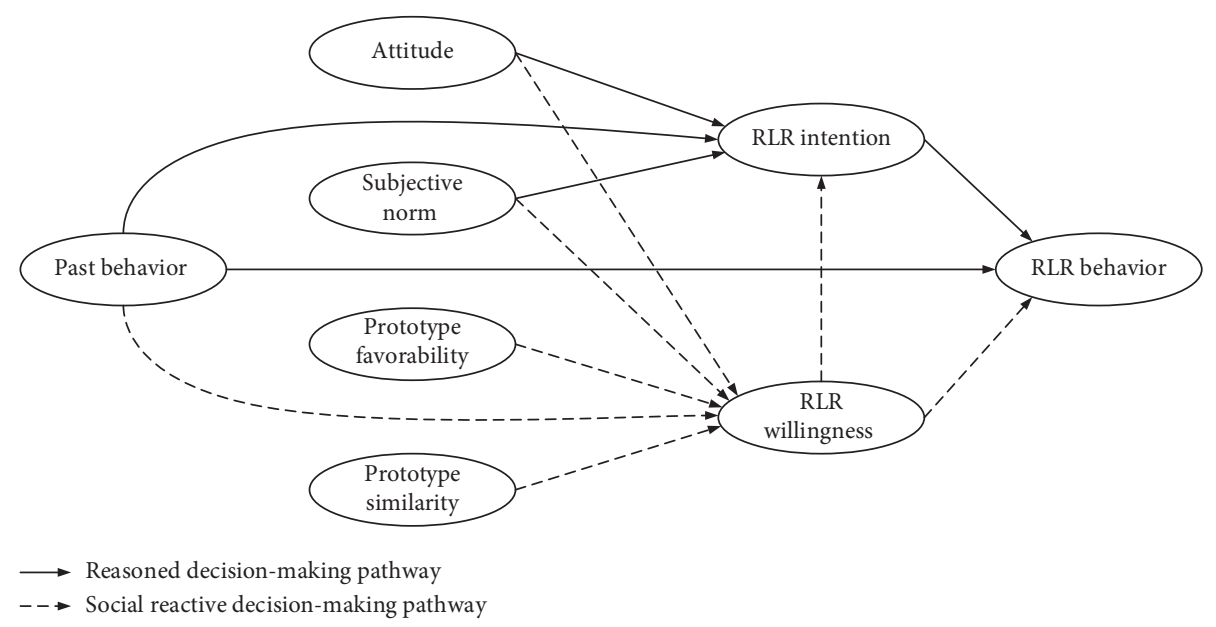

Figure 2: PWM framework.

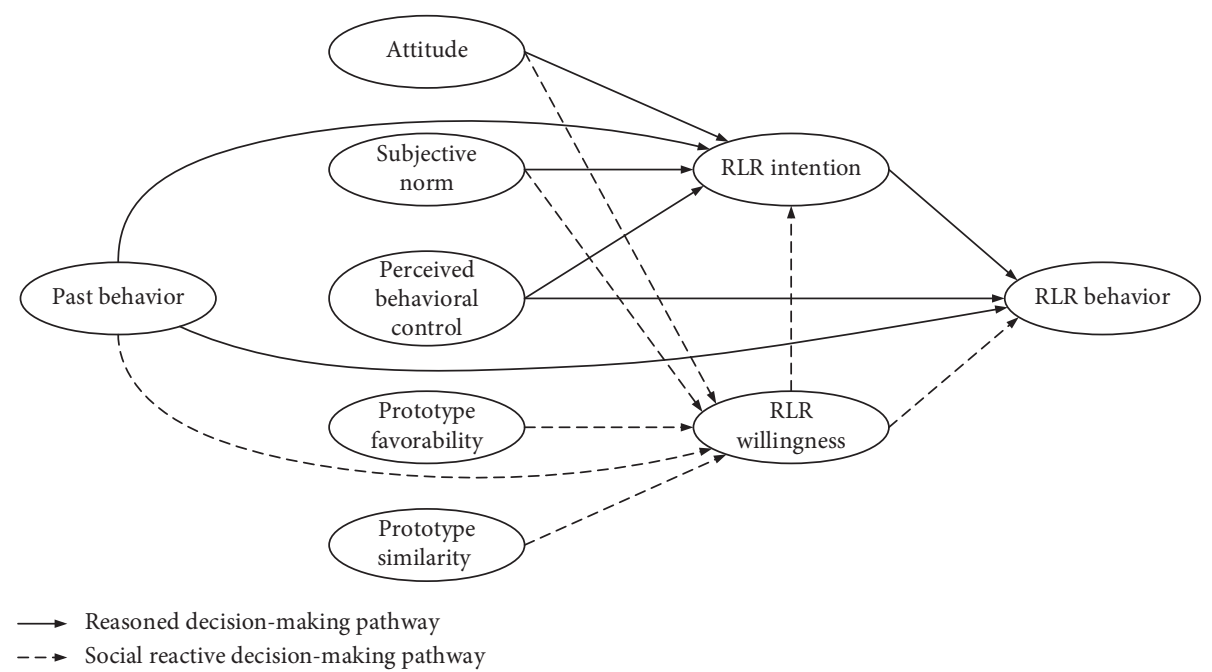

FIgURE 3: TPB-PWM framework.

employed to examine the reliability and validity of the items, and those items that did not pass the examinations were removed. The finalized questionnaire was designed based on the participants' feedback and the test results.

The formal survey was carried out in Shanghai, China, from May to July 2018. The participants were recruited from universities, communities, shopping malls, and office districts. They were required to complete two online questionnaires distributed by an online survey platform (http://www.wjx.cn) one month apart. To be specific, the participants were required to complete the first (Time 1) questionnaire, including all items of variables, except for RLR behavior (Table 1). One month later, the participants should complete the second (Time 2) questionnaire to measure the subsequent RLR behavior. Finally, the participants were rewarded with an amount of about $\$ 1$ for completing the survey.

2.2. Participants. In this survey, a total number of 1,147 participants completed the Time 1 and Time 2 questionnaires. After excluding 112 invalid questionnaires (e.g., inconsistent scoring logic, unusually short completion time, and abnormal score), we obtained a complete and valid sample of $N=1,035$ participants. The mean age of the final sample of participants was $34.6(\mathrm{SD}=9.92), 68.0 \%$ of which were female $(N=704) ; 89.2 \%$ used e-bikes at least twice a day on average $(N=923)$, and $74.3 \%$ had more than two years of e-bike riding experience $(N=769)$.

2.3. Measures. A 29-item questionnaire was designed to obtain data of participants for this work. The TPB-based items for each variable (i.e., attitude, subjective norm, perceived behavioral control, and RLR intention) and PWM-based items for each variable (i.e., past behavior, prototype perceptions, and RLR willingness) are presented in Table 1. Each item was measured using a 7-point response format. For the variables, we adopted the confirmatory factors analysis (CFA) and Cronbach's $\alpha$ correlation analysis to examine the validity and internal consistency of the items, thereby evaluating the reliability of the survey data. CFA was conducted by PCA. PCA identified that the value of 
TABLE 1: Summary of items and internal consistency.

\begin{tabular}{|c|c|c|c|c|c|c|}
\hline Variable & No. & & Item & Reference & $\begin{array}{c}\text { PCA } \\
(\%)\end{array}$ & $\begin{array}{c}\text { Cronbach's } \\
\alpha\end{array}$ \\
\hline Attitude & $\begin{array}{l}\text { AT1 } \\
\text { AT2 } \\
\text { AT3 } \\
\text { AT4 }\end{array}$ & $\begin{array}{l}\text { For me, running against a } \\
\text { red light in this situation } \\
\text { would be ... }\end{array}$ & $\begin{array}{c}\text { Bad to good } \\
\text { Foolish to wise } \\
\text { Dangerous to safe } \\
\text { Unnecessary to necessary }\end{array}$ & $\begin{array}{l}\text { Ajzen [43]; } \\
\text { Elliott et al. [47] }\end{array}$ & 72.5 & 0.873 \\
\hline $\begin{array}{l}\text { Subjective } \\
\text { norm }\end{array}$ & SN1 & \multicolumn{2}{|c|}{$\begin{array}{c}\text { People who are important to me disapprove of my red-light running in } \\
\text { this situation. (Strongly disagree to strongly agree) } \\
\text { People who are important to me bother with my red-light running in } \\
\text { this situation. (Strongly disagree to strongly agree) } \\
\text { People who are important to me tolerate my red-light running in this } \\
\text { situation. (Strongly disagree to strongly agree) }\end{array}$} & $\begin{array}{c}\text { Demir et al. [21]; } \\
\text { Ajzen [43] }\end{array}$ & 73.7 & 0.821 \\
\hline $\begin{array}{l}\text { Perceived } \\
\text { behavioral } \\
\text { control }\end{array}$ & $\begin{array}{l}\mathrm{PBC} 2 \\
\mathrm{PBC} 3\end{array}$ & \multicolumn{2}{|c|}{$\begin{array}{c}\text { I believe that I have the ability to run against a red light in this situation. } \\
\text { (Strongly disagree to strongly agree) } \\
\text { For me, it is easy to run against a red light in this situation. (Strongly } \\
\quad \text { disagree to strongly agree) } \\
\text { I have control over whether to violate a red light in this situation. } \\
\text { (Strongly disagree to strongly agree) }\end{array}$} & $\begin{array}{c}\text { Evans and } \\
\text { Norman [39] }\end{array}$ & 80.8 & 0.881 \\
\hline \multirow{3}{*}{$\begin{array}{l}\text { Prototype } \\
\text { perceptions }\end{array}$} & PB2 & \multicolumn{2}{|c|}{$\begin{array}{l}\text { How often have you committed the red-light running as an e-biker } \\
\text { during the last } 12 \text { months? (Never to frequently) } \\
\text { How often have you ridden faster than the legal speed limit during the } \\
\text { last } 12 \text { months? (Never to frequently) } \\
\text { How often have you committed the violating crossing as a pedestrian } \\
\text { during the last } 12 \text { months? (Never to frequently) }\end{array}$} & $\begin{array}{c}\text { Forward [29]; } \\
\text { Potard et al. [45] }\end{array}$ & 87.4 & 0.928 \\
\hline & PS1 & \multirow[b]{2}{*}{ Prototype favorability } & $\begin{array}{c}\text { How similar/different are you to/from the } \\
\text { person your age and gender that regularly } \\
\text { violates a red light? (Very different to very } \\
\text { similar) } \\
\text { I am comparable to the typical person my } \\
\text { age and gender that regularly violates a red } \\
\text { light. (Strongly disagree to strongly agree) } \\
\text { Do you resemble the typical person your age } \\
\text { and gender that regularly violates a red } \\
\text { light? (Definitely no to definitely yes) }\end{array}$ & \multirow{2}{*}{$\begin{array}{l}\text { Elliott et al. [47] } \\
\text { Elliott et al. [47] }\end{array}$} & 87.7 & 0.930 \\
\hline & $\begin{array}{l}\text { PF1 } \\
\text { PF2 } \\
\text { PF3 }\end{array}$ & & $\begin{array}{c}\text { How do you think about the } \\
\text { typical person your age and } \\
\text { gender who regularly violate a } \\
\text { red light? }\end{array}$ & & 89.4 & 0.940 \\
\hline RLR intention & $\mathrm{RI} 3$ & \multicolumn{2}{|c|}{$\begin{array}{l}\text { In such a situation, how likely is it that you will run against a red light? } \\
\text { (Extremely unlikely to extremely likely) } \\
\text { In a similar situation in the future, do you intend to run against a red } \\
\text { light? (Definitely do not to definitely do) } \\
\text { In a similar situation in the future, what is the degree that you will avoid } \\
\text { running against a red light? (Very weak to very strong) } \\
\text { In a similar situation in the future, how likely or unlikely is it that you } \\
\text { will run against a red light? (Extremely unlikely to extremely likely) }\end{array}$} & $\begin{array}{c}\text { Zhou et al. [40]; } \\
\text { Ajzen [43] }\end{array}$ & 82.2 & 0.928 \\
\hline RLR willingness & RW1 & \multicolumn{2}{|c|}{$\begin{array}{c}\text { You will wait for the green light to cross in this situation. (Not at all } \\
\text { willing to very willing) } \\
\text { You will run against a red light when there is a gap in traffic flow. (Not at } \\
\text { all willing to very willing) } \\
\text { If other e-bikers around you are running against a red light, what is the } \\
\text { degree that you will also run against a red light? (Very weak to very } \\
\text { strong) }\end{array}$} & $\begin{array}{l}\text { Elliott et al. [47]; } \\
\text { Gibbons et al. } \\
\text { [49] }\end{array}$ & 86.2 & 0.920 \\
\hline RLR behavior & RB3 & \multicolumn{2}{|c|}{$\begin{array}{l}\text { I have committed the red-light running in the last month. (Strongly } \\
\text { disagree to strongly agree) } \\
\text { How many times have you committed the red-light running over the } \\
\text { last month? (None to lots of times) } \\
\text { Overall, how often have you committed the red-light running over the } \\
\text { last month? (Never to frequently) }\end{array}$} & Elliott et al. [47] & 82.3 & 0.892 \\
\hline
\end{tabular}


Kaiser-Meyer-Olkin (KMO) was 0.973, and each single component accounted for $72.5 \%$ to $89.4 \%$ of the variance (Table 1), indicating the high validity of the items in the variable. All Cronbach's $\alpha$ coefficients ranged from 0.821 to 0.940, suggesting a high internal consistency (Cronbach's $\alpha>0.7$ ) (Table 1). Apart from these items, participants' demographic data (e.g., gender, age, use frequency, and years of riding experience) were also collected.

\section{Results}

3.1. Descriptive Statistics and Correlations. Table 2 summarizes the descriptive statistics of the variables. The participants reported that they had a negative attitude towards RLR behavior (attitude, mean $=2.79$ ). People who are important to participants (e.g., family members and friends), although subjectively disapprove them to run against a red light, would still tolerate their violating behaviors (subjective norm, mean $=2.52$ ). The participants had moderate control over their ability to violate a red light (perceived behavioral control, mean $=3.86$ ), and they violated traffic rules (e.g., red-light running, high-speeding, and violating crossing) to a moderate extent during the last 12 months (past behavior, mean $=4.24$ ). It is also visible in Table 2 that the participants regarded themselves slightly dissimilar to the prototypical RLR e-bikers (prototype similarity, mean $=3.80$ ) and rated the prototypical RLR e-bikers as moderately negative (prototype favorability, mean =3.74). Additionally, the participants had a weak intention to violate a red light (RLR intention, mean $=4.06$ ) but a relatively strong willingness to violate a red light whenever an opportunity was provided (RLR willingness, mean $=4.60$ ). Finally, the participants reported that they violated a red light to a moderate extent during one month after completing the Time 1 questionnaire (RLR behavior, mean $=4.20)$.

Pearson's bivariate correlations were calculated to evaluate the association between each variable (Table 2). The correlations established suggested that all study variables were significantly associated with each other. In particular, RLR intention, RLR willingness, and RLR behavior positively and significantly correlated with attitude, perceived behavioral control, past behavior, prototype similarity, and prototype favorability, while negatively and significantly with subjective norm. RLR behavior was positively and significantly related to RLR intention and willingness. The correlation analysis results support the efficacy of TPB, PWM, and TPB-PWM frameworks in explaining e-bikers' RLR behavior.

3.2. Results of the Structural Equation Modeling. In this section, we have presented the process and results of the path analysis conducted using structural equation modeling in Amos 24. The path models for e-bikers' RLR behavior was evaluated based on TPB, PWM, and TPB-PWM frameworks. Degree-of-fit of the proposed model frameworks was evaluated and modified by multiple indexes, including chisquare divided by degrees of freedom (CMIN/df), rootmean-square error of approximation (RMSEA), goodness- of-fit index (GFI), normal fit index (NFI), incremental fit index (IFI), comparative fit index (CFI), and Tucker-Lewis index (TLI) $[52,53]$. Subsequently, we employed the path analysis to estimate the significance of the direct, indirect, and total effects of the variables in each model and assess the predictive utility of the proposed models. The path analysis results of each model are presented below. The degree-of-fit indexes for three models are summarized in Table 3, while Table 4 displays the direct, indirect, and total effects of the independent variables on RLR intention, willingness, and behavior in three models.

3.2.1. TPB Model. Table 3 showed that the CMIN/df was more than 3 in the initial TPB model, indicating the degreeof-fit of this model to our data was inadequate (CMIN/ $\mathrm{df}=3.191, \quad \mathrm{RMESA}=0.046, \quad \mathrm{GFI}=0.953, \quad \mathrm{NFI}=0.969$, $\mathrm{IFI}=0.979, \mathrm{CFI}=0.979$, and $\mathrm{TLI}=0.975$ ). Based on the suggested modification indices in Amos 24, the initial model path was revised by adding a path from the subjective norm to past behavior. The modified TPB model fitted well to the data $(\mathrm{CMIN} / \mathrm{df}=2.925, \quad \mathrm{RMESA}=0.043, \quad \mathrm{GFI}=0.958$, $\mathrm{NFI}=0.972, \mathrm{IFI}=0.981, \mathrm{CFI}=0.981$, and $\mathrm{TLI}=0.978)$. The path analysis results revealed that the attitude, subjective norm, and perceived behavioral control were the crucial determiners of RLR intention. RLR behavior was also significantly predicted by RLR intention, perceived behavioral control, and past behavior. The modified TPB model explained $80.4 \%$ of the variance of RLR intention and $73.6 \%$ of RLR behavior (Figure 4).

3.2.2. PWM Model. The initial PWM model did not obtain a good fit to our data due to the value of more than 3 for the $\mathrm{CMIN} / \mathrm{df}(\mathrm{CMIN} / \mathrm{df}=3.246, \mathrm{RMESA}=0.047, \mathrm{GFI}=0.940$, $\mathrm{NFI}=0.965, \mathrm{IFI}=0.975, \mathrm{CFI}=0.975, \mathrm{TLI}=0.971)$. Thus, the initial model path was improved based on the suggested modification indices. We removed the path from subjective norm to RLR willingness and added the paths from prototype favorability and similarity to RLR intention, as well as the path from prototype favorability to RLR behavior. The modified PWM model obtained adequate degree-of-fit to the data $(\mathrm{CMIN} / \mathrm{df}=2.627, \quad \mathrm{RMESA}=0.040, \quad \mathrm{GFI}=0.951$, $\mathrm{NFI}=0.972$, IFI $=0.982, \mathrm{CFI}=0.982$, and $\mathrm{TLI}=0.979)$ and explained $76.6 \%, 77.4 \%$, and $81.3 \%$ of the variance of RLR intention, willingness, and behavior, respectively. It is noteworthy that RLR willingness had a greater impact on RLR behavior than $\operatorname{RLR}$ intention $(\beta=0.395$ vs $\beta=0.173)$ (Figure 5).

3.2.3. TPB-PWM Model. As the degree-of-fit of the initial TPB-PWM model to our data was inadequate (CMIN/ $\mathrm{df}=3.556, \quad \mathrm{RMESA}=0.050, \quad \mathrm{GFI}=0.923, \quad \mathrm{NFI}=0.956$, IFI $=0.968$, CFI $=0.968$, and TLI $=0.963$ ), we applied the same path modifications as those in the modified PWM model. Based on the modification indices, we also omitted the path from perceived behavioral control to RLR behavior. The modified TPB-PWM model fitted well to the data $(\mathrm{CMIN} / \mathrm{df}=2.438, \quad \mathrm{RMESA}=0.037, \quad \mathrm{GFI}=0.948$, 
TABle 2: Means, standard deviations, and bivariate correlations for all study variables.

\begin{tabular}{|c|c|c|c|c|c|c|c|c|c|c|c|}
\hline Variable & 1 & 2 & 3 & 4 & 5 & 6 & 7 & 8 & 9 & Mean & SD \\
\hline 1. Attitude & 1.000 & $-0.460^{* *}$ & $0.543^{* *}$ & $0.501^{* *}$ & $0.528^{* *}$ & $0.549^{* *}$ & $0.638^{* *}$ & $0.630^{* *}$ & $0.484^{* *}$ & 2.79 & 1.05 \\
\hline 2. Subjective norm & & 1.000 & $-0.572^{* *}$ & $-0.541^{* *}$ & $-0.643^{* *}$ & $-0.631^{* *}$ & $-0.582^{* *}$ & $-0.632^{* *}$ & $-0.689^{* *}$ & 2.52 & 1.19 \\
\hline 3. Perceived behavioral control & & & 1.000 & $0.631^{* *}$ & $0.701^{* *}$ & $0.675^{* *}$ & $0.760^{* *}$ & $0.622^{* *}$ & $0.680^{* *}$ & 3.86 & 1.54 \\
\hline 4. Past behavior & & & & 1.000 & $0.607^{* *}$ & $0.673^{* *}$ & $0.630^{* *}$ & $0.742^{* *}$ & $0.709^{* *}$ & 4.24 & 1.57 \\
\hline similarity & & & & & 1.000 & $0.772^{* *}$ & $0.711^{* *}$ & $0.685^{* *}$ & $0.778^{* *}$ & 3.80 & 1.87 \\
\hline e favorability & & & & & & 1.000 & $0.709^{* *}$ & $0.715^{* *}$ & $0.739^{* *}$ & 3.74 & 1.73 \\
\hline 7. RLR intention & & & & & & & 1.000 & $0.660^{* *}$ & $0.688^{* *}$ & 4.06 & 1.49 \\
\hline 8. RLR willingness & & & & & & & & 1.000 & $0.775^{* *}$ & 4.60 & 1.66 \\
\hline 9. RLR behavior & & & & & & & & & 1.000 & 4.20 & 1.41 \\
\hline
\end{tabular}

Note. ${ }^{* *} p<0.01$.

TABLE 3: The degree-of-fit indexes in three models.

\begin{tabular}{lcccccc}
\hline \multirow{2}{*}{ Index } & \multicolumn{2}{c}{ TPB model } & \multicolumn{2}{c}{ PWM model } & \multicolumn{2}{c}{ TPB-PWM model } \\
& Initial & Modified & Initial & Modified & Initial & Modified \\
\hline CMIN/df & 3.191 & 2.925 & 3.246 & 2.627 & 3.556 & 0.050 \\
RMESA & 0.046 & 0.043 & 0.047 & 0.040 & 0.038 \\
GFI & 0.953 & 0.958 & 0.940 & 0.951 & 0.923 & 0.956 \\
NFI & 0.969 & 0.972 & 0.965 & 0.982 & 0.968 & 0.970 \\
IFI & 0.979 & 0.981 & 0.975 & 0.982 & 0.968 \\
CFI & 0.979 & 0.981 & 0.975 & 0.979 & 0.963 & 0.982 \\
TLI & 0.975 & 0.978 & 0.971 & & 0.979 \\
\hline
\end{tabular}

TABLE 4: Effects of the independent variables on RLR intention, willingness, and behavior in three models.

\begin{tabular}{|c|c|c|c|c|c|c|c|c|c|}
\hline & \multicolumn{3}{|c|}{ RLR intention } & \multicolumn{3}{|c|}{ RLR willingness } & \multicolumn{3}{|c|}{ RLR behavior } \\
\hline & Direct & Indirect & Total & Direct & Indirect & Total & Direct & Indirect & Total \\
\hline \multicolumn{10}{|c|}{ TPB model } \\
\hline $\mathrm{AT}$ & $0.291^{* * *}$ & & $0.291^{* * *}$ & & & & & $0.079^{* * *}$ & $0.079^{* * *}$ \\
\hline SN & $-0.114^{* *}$ & $-0.027^{* *}$ & $-0.141^{* * *}$ & & & & & $-0.158^{* * *}$ & $-0.158^{* * *}$ \\
\hline $\mathrm{PBC}$ & $0.527^{* * *}$ & $0.048^{* *}$ & $0.575^{* * *}$ & & & & $0.254^{* * *}$ & $0.369^{* * *}$ & $0.623^{* * *}$ \\
\hline $\mathrm{PB}$ & $0.094^{* *}$ & & $0.094^{* *}$ & & & & $0.420^{* * *}$ & $0.025^{* *}$ & $0.445^{* * *}$ \\
\hline RI & & & & & & & $0.270^{* * *}$ & & $0.270^{* * *}$ \\
\hline \multicolumn{10}{|c|}{ PWM model } \\
\hline $\mathrm{AT}$ & $0.361^{* * *}$ & -0.026 & $0.335^{* * *}$ & $0.257^{* * *}$ & & $0.257^{* * *}$ & & $0.160^{* * *}$ & $0.160^{* * *}$ \\
\hline $\mathrm{SN}$ & $-0.073^{*}$ & & $-0.073^{*}$ & & & & & $-0.013^{*}$ & $-0.013^{*}$ \\
\hline $\mathrm{PB}$ & $0.196^{* * *}$ & -0.044 & $0.152^{* * *}$ & $0.434^{* * *}$ & & $0.434^{* * *}$ & $0.140^{* *}$ & $0.197^{* * *}$ & $0.337^{* * *}$ \\
\hline $\mathrm{PF}$ & $0.132^{*}$ & $-0.013^{*}$ & 0.119 & $0.127^{*}$ & & $0.127^{*}$ & $0.285^{* * *}$ & $0.071^{* * *}$ & $0.356^{* * *}$ \\
\hline PS & $0.364^{* * *}$ & $-0.021^{*}$ & $0.343^{* * *}$ & $0.203^{* * *}$ & & $0.203^{* * *}$ & & $0.139^{* * *}$ & $0.139^{* * *}$ \\
\hline RW & -0.102 & & -0.102 & & & & $0.395^{* * *}$ & $-0.018^{*}$ & $0.377^{* * *}$ \\
\hline RI & & & & & & & $0.173^{* * *}$ & & $0.173^{* * *}$ \\
\hline \multicolumn{10}{|c|}{ TPB-PWM model } \\
\hline $\mathrm{AT}$ & $0.282^{* * *}$ & -0.014 & $0.268^{* * *}$ & $0.256^{* * *}$ & & $0.256^{* * *}$ & & $0.148^{* * *}$ & $0.148^{* * *}$ \\
\hline SN & -0.036 & & -0.036 & & & & & -0.006 & -0.006 \\
\hline $\mathrm{PBC}$ & $0.428^{* * *}$ & & $0.428^{* * *}$ & & & & & $0.075^{* * *}$ & $0.075^{* * *}$ \\
\hline $\mathrm{PB}$ & 0.075 & -0.023 & 0.052 & $0.432^{* * *}$ & & $0.432^{* * *}$ & $0.142^{* *}$ & $0.179^{* * *}$ & $0.321^{* * *}$ \\
\hline $\mathrm{PF}$ & 0.082 & -0.007 & 0.075 & $0.132^{*}$ & & $0.132^{*}$ & $0.283^{* * *}$ & $0.065^{* * *}$ & $0.348^{* * *}$ \\
\hline PS & $0.191^{* * *}$ & -0.011 & $0.180^{* * *}$ & $0.199^{* * *}$ & & $0.199^{* * *}$ & & $0.110^{* * *}$ & $0.110^{* * *}$ \\
\hline RW & -0.054 & & -0.054 & & & & $0.393^{* * *}$ & -0.009 & $0.384^{* * *}$ \\
\hline RI & & & & & & & $0.175^{* * *}$ & & $0.175^{* * *}$ \\
\hline
\end{tabular}

Note. ${ }^{*}<0.05 ;{ }^{* *} p<0.01 ;{ }^{* * *} p<0.001$.

$\mathrm{NFI}=0.970, \mathrm{IFI}=0.982, \mathrm{CFI}=0.982$, and $\mathrm{TLI}=0.979)$ and explained a relatively higher percentage of the variance of RLR intention (82.0\%), behavior willingness (77.1\%), and
RLR behavior (81.4\%). We also found that RLR willingness contributed more impact on RLR behavior compared to RLR intention $(\beta=0.393$ vs $\beta=0.175$ ) (Figure 6). 


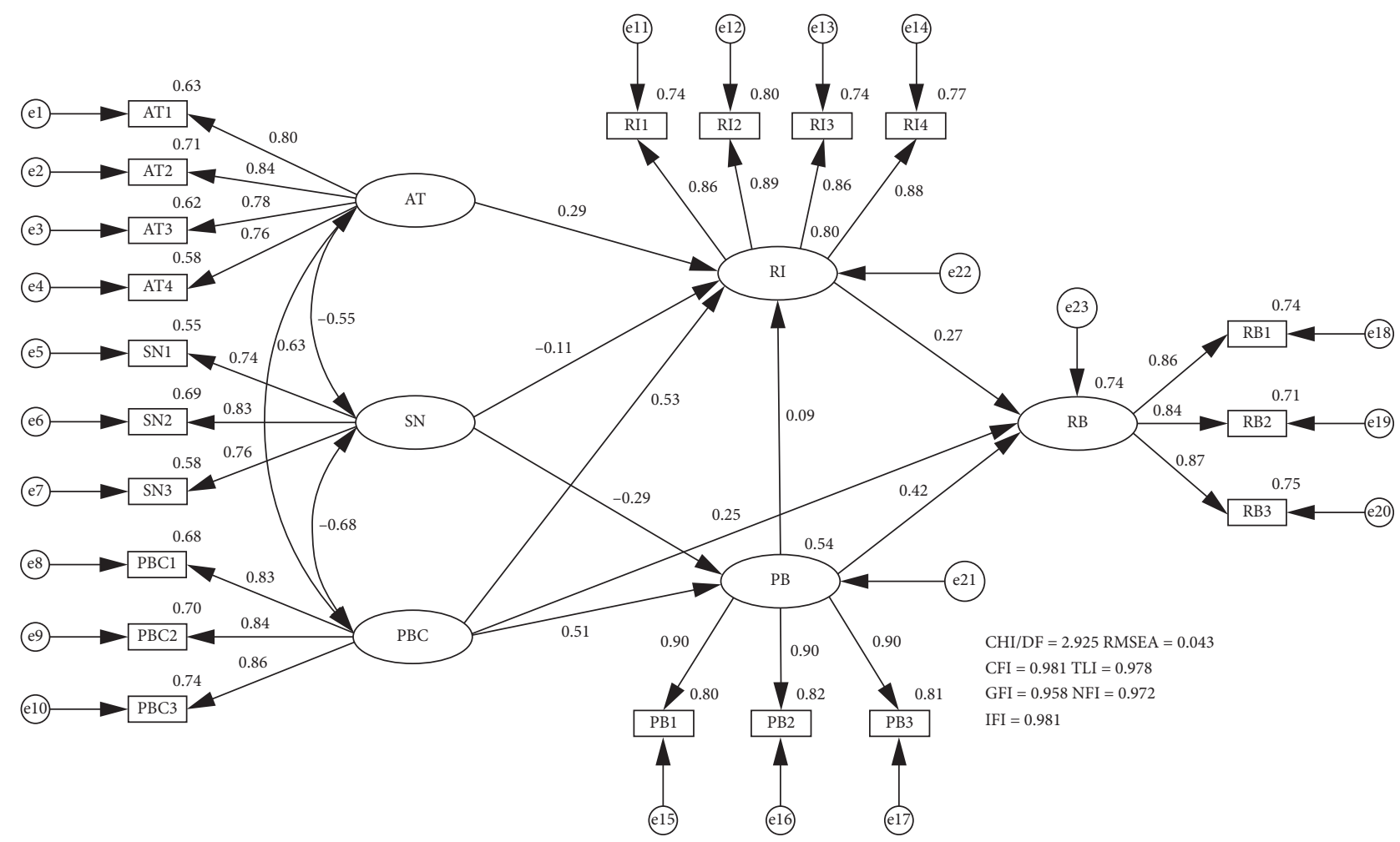

FIgURE 4: The modified TPB model for e-bikers' RLR behavior.

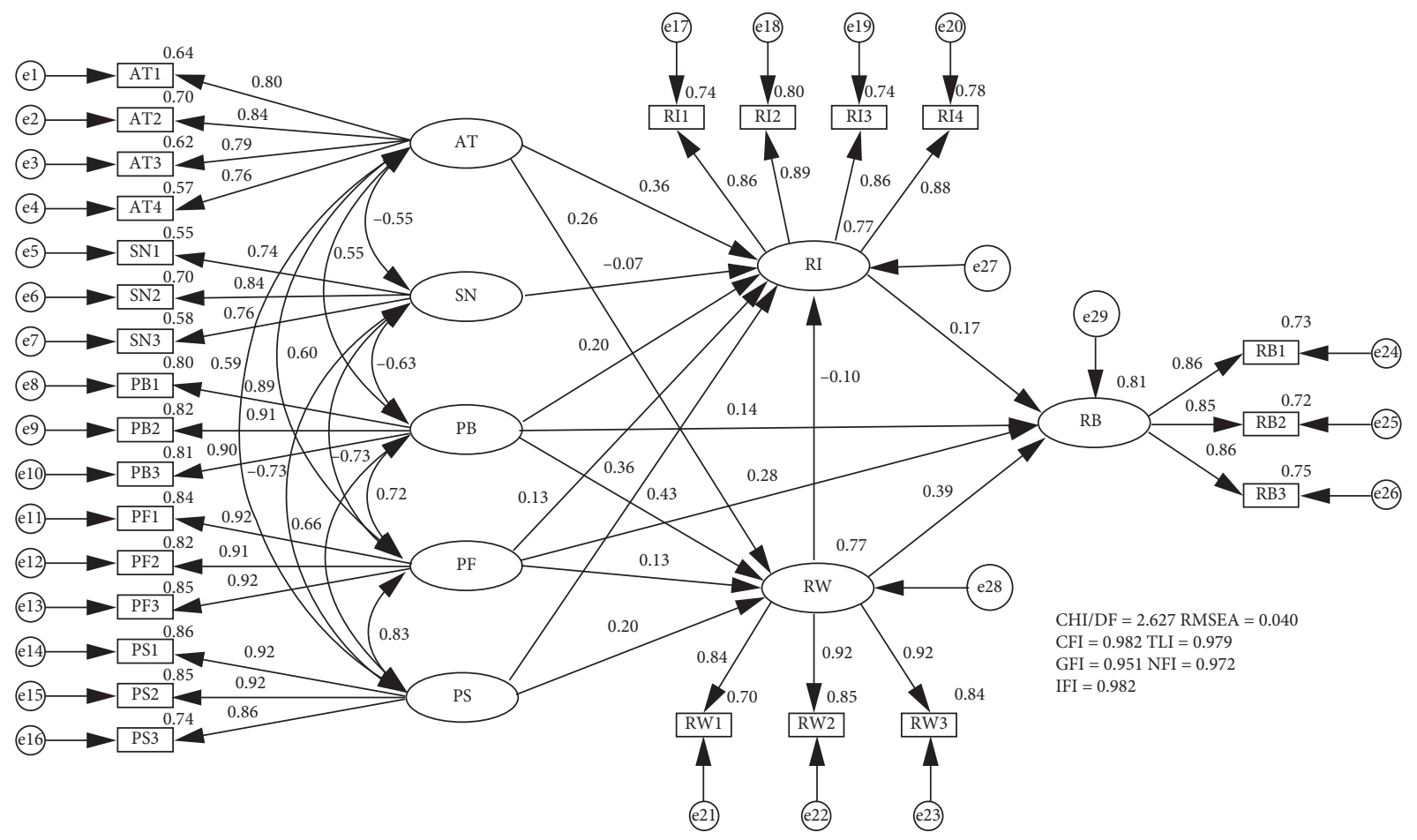

FIgURE 5: The modified PWM model for e-bikers' RLR behavior.

\section{Discussion}

4.1. Comparison of Predictive Utility. As shown in Tables 3 and 4, the modified TPB, PWM, and TPB-PWM models provided adequate degree-of-fit to the data, but the modified
PWM and TPB-PWM models had a more considerable utility in predicting e-bikers' RLR behavior than the modified TPB model. That is, the PWM and TPB-PWM frameworks provided a more complete account of e-bikers' RLR behavior than the TPB framework. 


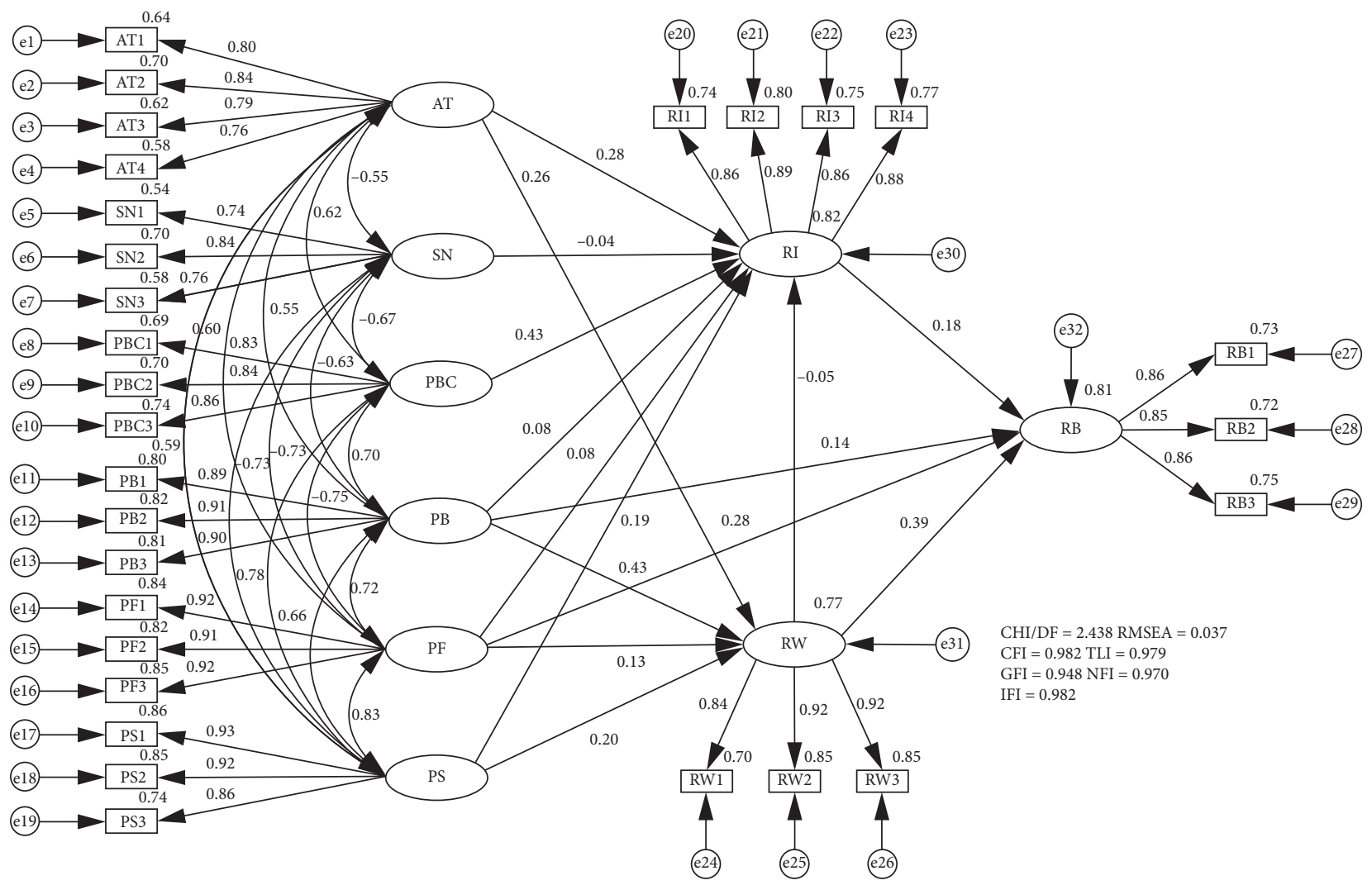

Figure 6: The modified TPB-PWM model for e-bikers' RLR behavior.

4.1.1. Predictive Utility of $T P B$. In this study, the extended TPB model with the addition of past behavior explained $80.4 \%$ of the variance of RLR intention and $73.6 \%$ of RLR behavior. Previous studies obtained similar results, reporting that the TPB framework explained $25 \%-72.8 \%$ of the variance in pedestrians' violation intentions [38-41]. However, these studies focused on predicting pedestrians' behavioral intention but not on their behavior. Demir et al. [21] confirmed the path from intention to behavior for pedestrians' violations. Currently, insufficient evidence exists on the intention-behavior path for e-bikers' violations.

All the variables from the TPB framework had a statistically significant total effect on RLR intention and behavior. Of these variables, perceived behavioral control had the highest total effect (the sum of the direct and indirect effects) on RLR intention, which can be supported across a few studies on pedestrians' violation intention and drinkdriving intention [41, 45]. Also, the total effect of perceived behavioral control on e-bikers' RLR behavior was the strongest. In accordance with earlier related findings on pedestrians' violations [21], perceived behavioral control also played an important role in predicting pedestrians' violating behavior. However, in contrast to the results obtained by Demir et al. [21], we established that the subjective norm was statistically significantly associated with RLR intention and behavior. This result was in line with previous research studies which revealed that subjective norm contributed a moderate effect on pedestrians' violation intentions [39, 40,54]. Among the extended TPB framework, past behavior as an extended variable contributed a weak effect on RLR intention, which is inconsistent with the related studies on the behavioral intentions of risky riding [30] and drink-driving [31, 45]. However, past behavior was found to be a second-crucial determiner of RLR behavior and added an additional $7.2 \%$ to the explained variance for RLR behavior compared to the original TPB model. This result was in good agreement with a previous study on drivers' speeding behavior [55], which reported that the additional past behavior could enhance the explained variance for speeding behavior by an additional 4\%. Our findings highlighted the fact that past behavior, with the incorporation into the original TPB framework, improved the predictive power. To some extent, e-bikers' past behavior partially represented their behavioral habits, while the habitual, familiar behavior has been recognized by Ajzen [42] that plays an important role in predicting behavior.

\subsubsection{Predictive Utility of $P W M$ and TPB-PWM.} Compared to the modified TPB framework, the modified PWM and TPB-PWM frameworks explained an additional $7.7 \%$ and $7.8 \%$ of the variance in RLR behavior. The modified TPB-PWM framework also explained an additional $1.6 \%$ of the variance in RLR intention. Interestingly, our findings showed that RLR intention and willingness were crucial predictors of RLR behavior, and the total effect of willingness on RLR behavior was prominently stronger than that of intention. Elliott et al. [47] and Demir et al. [21] 
reached similar conclusions for drivers' speeding and pedestrians' violations. They also revealed that behavioral willingness contributed more substantially to violating behavior than behavioral intention. Thus, we concluded that e-bikers might decide on whether to violate a red light through the social reactive pathway rather than the reasoned pathway. This result was also consistent with the conclusions of Gibbons et al. [49], which underlined that the social reactive decision-making was more suitable for predicting risk-taking behavior. Accordingly, as expected, the results revealed that social reactive decision-making is more crucial than reasoned decision-making in determining e-bikers' RLR behavior. This finding is paralleled to the dynamic nature of the riding task, which suggests that social reactive decision-making needs to respond to changing traffic environmental factors.

The model estimation results revealed that the attitude still significantly influenced RLR intention as the TPB model, and furthermore, had a significant total effect on RLR behavior via a mediator variable "RLR willingness." However, the influence of subjective norm on RLR intention and behavior was weakened, and it was no longer a significant variable in the TPB-PWM model. A plausible reason is that the approval of one's family members or friends on RLR behavior has little influence on his/her RLR intention and behavior, which is supported by the results of several investigations on violation intentions of drivers, e-bikers, and pedestrians $[17,21,29,32,40]$. For instance, Zhou et al. [40] suggested that the behavior of pedestrian's family members or friends exerts a stronger influence on the pedestrian's intention to violate crossing than their approval of such behavior.

Prototype perceptions (favorability and similarity) played a significant role in predicting RLR intention, willingness, and behavior, except for a special case; that is, the effect of prototype favorability on RLR intention was not significant in the TPB-PWM model, which was caused by the addition of perceived behavioral control. These results revealed that e-bikers who perceived people of their age and gender that regularly violate a red light as favorable and similar had a higher intention/willingness to commit RLR behavior. Although the original PWM framework has no relationship between prototype perceptions and intention, recent studies on pedestrian violations also found that prototype perceptions significantly contributed to intention [47]. More specifically, in the modified PWM model, prototype perceptions had a more significant influence on RLR intention than RLR willingness. Since perceived behavioral control was integrated into the modified TPB-PWM model and significantly influenced RLR intention, prototype perceptions contributed to RLR willingness more considerably.

Perceived behavioral control, as one of the TPB-based variables, still exerted a strong influence on RLR intention, whereas it had a weak effect on RLR behavior since it did not directly affect RLR behavior. In the modified PWM, past behavior was always a crucial predictor of RLR intention, willingness, and behavior, as also established by Gibbons et al. $[20,49]$. In the modified TPB-PWM model, although the effect of past behavior on RLR intention was no more significant due to the addition of perceived behavioral control, past behavior still substantially contributed to RLR willingness and behavior. These findings revealed that e-bikers' perceived ability to violate a red light (perceived behavioral control) was more likely to influence behavioral intention, whereas behavioral habits or experiences (past behavior) had a greater impact on their behavioral willingness. In summary, e-bikers' behavioral habits or experiences substantially influence RLR behavior through social reactive and reasoned pathways. Therefore, bias and deviations in the final results might have been caused in Demir et al.'s [21] study without considering the impact of past behavior.

4.2. Implications of Safety Interventions. The outputs obtained from this study could support the application of safety interventions and thereby further discourage the e-bikers' RLR behavior. The attitude, perceived behavioral control, past behavior, prototype perceptions, RLR intention, and RLR willingness represent particularly good intervention targets since they were the crucial predictors of e-bikers' RLR behavior.

Among these identified psychological factors, the perceived behavioral control was a crucial contributor to e-bikers' RLR intention. This result revealed that if e-bikers perceived the difficulty of violating a red light, they had less intention to commit it. Thus, reducing e-bikers' perceived control might decrease their RLR behavior. For example, radio-frequency identification (RFID) can be integrated into e-bike license plates, combined with traffic cameras, to automatically monitor and capture e-bikes' RLR behavior at signalized intersections. Meanwhile, learning from the management system of drivers' red-light infringement behavior, more stringent penalties (e.g., higher fines and demerit point system) can be employed to limit the e-bikers' RLR behavior. The RLR willingness was especially crucial for RLR behavior. The aforementioned countermeasures would also reduce the opportunity for RLR behavior, thereby weakening the willingness to violate a red light.

Since attitude, prototype perceptions, and past behavior were found to be pronounced predictors of both intention and willingness to engage in RLR behavior, preventative safety interventions are needed to focus on addressing this issue. Therefore, future advertisements and education related to traffic safety could consider creating the images of negative and undesirable e-bikers who violate a red light and enhance the negative and unfavorable perception of the most typical violators. For instance, riding simulation could allow e-bikers to experience traffic crashes or near-crashes as the results of their RLR behavior at signalized intersections, which might make e-bikers directly perceive the negative attributes of RLR behavior. It is expected that identifying violating e-bikers with negative portrayal would reduce e-bikers' RLR behavior. This expectation is supported by the findings of Demir et al. [56], which indicated that identifying speeders with negative portrayal on campus could reduce the incidence of speeding behavior. Also, school-based education can be an important approach to changing or correcting individual attitudes and prototype perceptions, especially correcting younger people's attitudes and prototype 
perceptions [40]. In essence, past behavior can indicate individual behavioral habits [42]. Therefore, the proposed advertisements and education, riding simulation, and automated traffic rule enforcement might help e-bikers develop good riding habits. Furthermore, if e-bikers are required to participant in e-bike riding training and pass some riding tests, their illegal riding habits might be corrected.

4.3. Limitations and Future Research. This study employed the social cognitive theories, including the TPB, PWM, and TPB-PWM frameworks, in understanding e-bikers' RLR behavior. Our work extended upon previous studies in e-bikers' RLR behavior which was investigated by using the TPB frameworks. Furthermore, the application of the PWM and TPB-PWM frameworks allowed for an in-depth understanding of the psychological factors influencing e-bikers' RLR behavior. Despite this, our work still had some limitations that need attention and discussion. First, the study sample included e-bikers that were predominantly female and with a large age variance. Previous studies showed that men or young people are more prone to take the risk when driving or riding; also their likelihood to get involved in traffic accidents is greater [11-15, 57, 58]. Hence, the gender and age composition of the study sample might have influenced the results of the proposed model frameworks. More comprehensive studies need to be conducted to elucidate the effects of gender and age differences in the future. Second, the findings of this study might have been affected by the bias inherent in self-report data. Specifically, such bias might have led to an underestimation of past behavior and subsequent RLR behavior due to social desirability and recall bias. Although this work was conducted by the use of voluntary and anonymous questionnaires to reduce social desirability bias, recall bias was still an issue that needed to be addressed. Third, one aim of this study is to predict potential RLR behavior, which requires high accuracy for measuring subsequent RLR behavior, whereas we measured this variable only by self-reports. Therefore, the absence of an objective measurement of subsequent RLR behavior is also a major limitation of this work. In future studies, we can use some objective measurements such as an e-bike data acquisition system to obtain the frequency of subsequent RLR behavior in a given period (one month or more) after completing the Time 1 questionnaire. The fourth limitation is that this study assumes that the use of e-bikes of participants is an equal amount, whereas it varies significantly between participants based on the collected metric of exposure (e.g., use frequency and years of riding experience). As the exposure might be correlated to the psychological variables, the study results would be altered. Therefore, the influence of the exposure factors on the psychological variables and behavior should be considered in future work.

\section{Conclusions}

The findings of our research suggest that the TPB and PWM are the promising theoretical frameworks for predicting e-bikers' intention or willingness to engage in RLR behavior, as well as for understanding the effects of psychological variables on RLR behavior. Furthermore, the PWM and TPB-PWM frameworks were found to be superior to the TPB framework in predicting e-bikers' RLR behavior. The present findings validate our hypothesis that e-bikers' RLR behavior is governed by both reasoned and social reactive decision-making, and the influence of the latter is stronger. In the PWM model, attitude, past behavior, and prototype similarity were the crucial predictors of both RLR intention and willingness. Prototype favorability had a relatively weak influence on RLR intention and willingness while exerted a pronounced direct effect on RLR behavior. In the TPB-PWM model, with the addition of perceived behavioral control, the impact of past behavior on RLR intention was reduced by the substantial influence of perceived behavioral control on RLR intention, but past behavior was still a crucial factor in predicting RLR behavior. These results imply the significance of specifically changing the e-bikers' attitude, perceived behavioral control, past behavior, and prototype perceptions towards RLR behavior. Thus, the design of more effective behavior-change interventions is needed, such as advertisements and education, training programs (e.g., riding simulation, riding training, and riding tests), and automated traffic rule enforcement.

\section{Data Availability}

The data used to support the findings of this study are available from the corresponding author upon request.

\section{Conflicts of Interest}

The authors declare that there are no conflicts of interest regarding the publication of this paper.

\section{Authors' Contributions}

T. Tang, H. Wang, and X. Zhou were responsible for study conception and design. H. Gong and $\mathrm{H}$. Wang were involved in data collection. T. Tang, H. Wang, and H. Gong carried out analysis and interpretation of results. T. Tang and X. Zhou prepared the draft manuscript. All authors reviewed the results and approved the final version of the manuscript.

\section{Acknowledgments}

This research was supported by the Natural Science Foundation of the Jiangsu Higher Education Institutions of China (no. 19KJB580003), the Science and Technology Project of Nantong City (no. JC2019062), the Science and Technology Project of Jiangsu Province, China (no. BK20190926), the National Natural Science Foundation Council of China (no. 71601142), and the Applied Research Foundation of Social Science of Jiangsu Province (no. 19SYC-110).

\section{References}

[1] S. Papoutsi, L. Martinolli, C. T. Braun, and A. K. Exadaktylos, "E-bike injuries: experience from an urban emergency department-a retrospective study from Switzerland," Emergency Medicine International, vol. 2014, p. 5, 2014. 
[2] A. Fyhri, O. Johansson, and T. Bjørnskau, "Gender differences in accident risk with e-bikes-survey data from Norway," Accident Analysis \& Prevention, vol. 132, Article ID 105248, 2019.

[3] P. Schepers, K. K. Wolt, and E. Fishman, "The safety of E-bikes in The Netherlands," International Transport Forum Discussion Papers, 2018.

[4] D. Zuev, D. Tyfield, and J. Urry, "Where is the politics? E-bike mobility in urban China and civilizational government," Environmental Innovation and Societal Transitions, vol. 30, pp. 19-32, 2019.

[5] J. P. Schepers, E. Fishman, P. Den Hertog, K. K. Wolt, and A. L. Schwab, "The safety of electrically assisted bicycles compared to classic bicycles," Accident Analysis \& Prevention, vol. 73, pp. 174-180, 2014.

[6] T. Weber, G. Scaramuzza, and K.-U. Schmitt, "Evaluation of E-bike accidents in Switzerland," Accident Analysis \& Prevention, vol. 73, pp. 47-52, 2014.

[7] Traffic Management Bureau of the Ministry of Public Security, "The people's republic of China road traffic accident annual statistic report," Traffic Management Bureau of the Ministry of Public Security, Wuxi, China, 2018.

[8] Q. Chen and B. Dai, "Characteristics and casualty analysis of two-wheeler accidents in China, data source: the China indepth accident study (CIDAS)," SAE Technical Paper, vol. 2018, 2018.

[9] H. P. A. M. Poos, T. L. Lefarth, J. S. Harbers, K. W. Wendt, M. El Moumni, and I. H. F. Reininga, "E-bikers are more often seriously injured in bicycle accidents: results from the Groningen bicycle accident database," Nederlands Tijdschrift Voor Geneeskunde, vol. 161, Article ID D1529, 2017.

[10] F. Chen, M. Song, and X. Ma, "Investigation on the injury severity of drivers in rear-end collisions between cars using a random parameters bivariate ordered probit model," International Journal of Environmental Research and Public Health, vol. 16, no. 14, p. 2632, 2019.

[11] M. Johnson, S. Newstead, J. Charlton, and J. Oxley, "Riding through red lights: the rate, characteristics and risk factors of non-compliant urban commuter cyclists," Accident Analysis \& Prevention, vol. 43, no. 1, pp. 323-328, 2011.

[12] M. Johnson, J. Charlton, J. Oxley, and S. Newstead, "Why do cyclists infringe at red lights? An investigation of Australian cyclists' reasons for red light infringement," Accident Analysis \& Prevention, vol. 50, no. 1, pp. 840-847, 2013.

[13] C. Wu, L. Yao, and K. Zhang, "The red-light running behavior of electric bike riders and cyclists at urban intersections in China: an observational study," Accident Analysis \& Prevention, vol. 49, no. 11, pp. 186-192, 2012.

[14] C.-W. Pai and R.-C. Jou, "Cyclists' red-light running behaviours: an examination of risk-taking, opportunistic, and law-obeying behaviours," Accident Analysis \& Prevention, vol. 62, pp. 191-198, 2014.

[15] F. Fraboni, V. Marín Puchades, M. De Angelis, L. Pietrantoni, and G. Prati, "Red-light running behavior of cyclists in Italy: an observational study," Accident Analysis \& Prevention, vol. 120, pp. 219-232, 2018.

[16] D. De Waard, F. Westerhuis, and B. Lewis-Evans, "More screen operation than calling: the results of observing cyclists" behaviour while using mobile phones," Accident Analysis \& Prevention, vol. 76, pp. 42-48, 2015.

[17] H. Yang, X. Liu, F. Su, C. Cherry, Y. Liu, and Y. Li, "Predicting e-bike users' intention to run the red light: an application and extension of the theory of planned behavior," Transportation
Research Part F: Traffic Psychology and Behaviour, vol. 58, pp. 282-291, 2018.

[18] P. Sheeran, P. M. Gollwitzer, and J. A. Bargh, "Nonconscious processes and health," Health Psychology, vol. 32, no. 5, pp. 460-473, 2013.

[19] M. Conner and P. Sparks, "The theory of planned behaviour and health behaviours," in Predicting Health Behaviour: Research and Practice with Social Cognition Models, M. Conner and P. Norman, Eds., pp. 170-222, Open University Press, Maidenhead, UK, 2nd edition, 2005.

[20] F. X. Gibbons, A. E. Houlihan, and M. Gerrard, "Reason and reaction: the utility of a dual-focus, dual-processing perspective on promotion and prevention of adolescent health risk behaviour," British Journal of Health Psychology, vol. 14, no. 2, pp. 231-248, 2009.

[21] B. Demir, T. Özkan, and S. Demir, "Pedestrian violations: reasoned or social reactive? Comparing theory of planned behavior and prototype willingness model," Transportation Research Part F: Traffic Psychology and Behaviour, vol. 60, pp. 560-572, 2019.

[22] D. De Waard, P. Schepers, W. Ormel, and K. Brookhuis, "Mobile phone use while cycling: incidence and effects on behaviour and safety," Ergonomics, vol. 53, no. 1, pp. 30-42, 2010 .

[23] K. Kircher, C. Ahlstrom, L. Palmqvist, and E. Adell, "Bicyclists' speed adaptation strategies when conducting self-paced vs. system-paced smartphone tasks in traffic," Transportation Research Part F: Traffic Psychology and Behaviour, vol. 28, pp. 55, 64-64, 2015.

[24] X. Yang, M. Huan, B. Si, L. Gao, and H. Guo, "Crossing at a red light: behavior of cyclists at urban intersections," Discrete Dynamics in Nature and Society, vol. 2012, Article ID 490810, 12 pages, 2012.

[25] X. Yang, M. Abdel-Aty, M. Huan, B. Jia, and Y. Peng, "The effects of traffic wardens on the red-light infringement behavior of vulnerable road users," Transportation Research Part F: Traffic Psychology and Behaviour, vol. 37, pp. 52-63, 2016.

[26] Y. Zhang and $\mathrm{C}$. Wu, "The effects of sunshields on red light running behavior of cyclists and electric bike riders," Accident Analysis \& Prevention, vol. 52, pp. 210-218, 2013.

[27] X. Yang, M. Huan, M. Abdel-Aty, Y. Peng, and Z. Gao, “A hazard-based duration model for analyzing crossing behavior of cyclists and electric bike riders at signalized intersections," Accident Analysis \& Prevention, vol. 74, pp. 33-41, 2015.

[28] K. Schleinitz, T. Petzoldt, S. Kröling, T. Gehlert, and S. Mach, "(E-)cyclists running the red light-the influence of bicycle type and infrastructure characteristics on red light violations," Accident Analysis \& Prevention, vol. 122, pp. 99-107, 2019.

[29] S. E. Forward, "The theory of planned behaviour: the role of descriptive norms and past behaviour in the prediction of drivers' intentions to violate," Transportation Research Part F: Traffic Psychology and Behaviour, vol. 12, no. 3, pp. 198-207, 2009.

[30] K. Chorlton, M. Conner, and S. Jamson, "Identifying the psychological determinants of risky riding: an application of an extended theory of planned behaviour," Accident Analysis \& Prevention, vol. 49, pp. 142-153, 2012.

[31] D. C. N. Chan, A. M. S. Wu, and E. P. W. Hung, "Invulnerability and the intention to drink and drive: an application of the theory of planned behavior," Accident Analysis \& Prevention, vol. 42, no. 6, pp. 1549-1555, 2010.

[32] I. S. Moan and J. Rise, "Predicting intentions not to "drink and drive" using an extended version of the theory of planned 
behaviour," Accident Analysis \& Prevention, vol. 43, no. 4, pp. 1378-1384, 2011.

[33] C. Castanier, T. Deroche, and T. Woodman, "Theory of planned behaviour and road violations: the moderating influence of perceived behavioural control," Transportation Research Part F: Traffic Psychology and Behaviour, vol. 18, pp. 148-158, 2013.

[34] H. E. Nemme and K. M. White, "Texting while driving: psychosocial influences on young people's texting intentions and behaviour," Accident Analysis \& Prevention, vol. 42, no. 4, pp. 1257-1265, 2010.

[35] R. Zhou, P.-L. P. Rau, W. Zhang, and D. Zhuang, "Mobile phone use while driving: predicting drivers' answering intentions and compensatory decisions," Safety Science, vol. 50, no. 1, pp. 138-149, 2012.

[36] K. Brijs, S. Daniels, T. Brijs, and G. Wets, "An experimental approach towards the evaluation of a seat belt campaign with an inside view on the psychology behind seat belt use," Transportation Research Part F: Traffic Psychology and Behaviour, vol. 14, no. 6, pp. 600-613, 2011.

[37] K. Okamura, G. Fujita, M. Kihira, R. Kosuge, and T. Mitsui, "Predicting motivational determinants of seatbelt non-use in the front seat: a field study," Transportation Research Part F: Traffic Psychology and Behaviour, vol. 15, no. 5, pp. 502-513, 2012.

[38] B. Gannon, L. Rosta, M. Reeve, M. K. Hyde, and I. Lewis, "Does it matter whether friends, parents, or peers drink walk? Identifying which normative influences predict young pedestrian's decisions to walk while intoxicated," Transportation Research Part F: Traffic Psychology and Behaviour, vol. 22, pp. 12-24, 2014.

[39] D. Evans and P. Norman, "Predicting adolescent pedestrians' road-crossing intentions: an application and extension of the theory of planned behaviour," Health Education Research, vol. 18, no. 3, pp. 267-277, 2003.

[40] H. Zhou, S. B. Romero, and X. Qin, "An extension of the theory of planned behavior to predict pedestrians' violating crossing behavior using structural equation modeling," Accident Analysis and Prevention, vol. 95, pp. 4717-424, 2016.

[41] B. K. Barton, S. M. Kologi, and A. Siron, "Distracted pedestrians in crosswalks: an application of the theory of planned behavior," Transportation Research Part F: Traffic Psychology and Behaviour, vol. 37, pp. 129-137, 2016.

[42] I. Ajzen, "From intentions to actions: a theory of planned behavior," in Action Control from Cognition to Behavior, J. Kuhl and J. Beckman, Eds., Springer, Heidelberg, Germany, pp. 11-39, 1985.

[43] I. Ajzen, "The theory of planned behavior," Organizational Behavior and Human Decision Processes, vol. 50, no. 2, pp. 179-211, 1991.

[44] S. Bamberg, I. Ajzen, and P. Schmidt, "Choice of travel mode in the theory of planned behavior: the roles of past behavior, habit, and reasoned action," Basic and Applied Social Psychology, vol. 25, no. 3, pp. 175-187, 2003.

[45] C. Potard, V. Kubiszewski, G. Camus, R. Courtois, and S. Gaymard, "Driving under the influence of alcohol and perceived invulnerability among young adults: an extension of the theory of planned behavior," Transportation Research Part F: Traffic Psychology and Behaviour, vol. 55, pp. 38-46, 2018.

[46] A. Rivis, C. Abraham, and S. Snook, "Understanding young and older male drivers' willingness to drive while intoxicated: the predictive utility of constructs specified by the theory of planned behaviour and the prototype willingness model,"
British Journal of Health Psychology, vol. 16, no. 2, pp. 445456, 2011.

[47] M. A. Elliott, R. McCartan, S. E. Brewster, D. Coyle, L. Emerson, and K. Gibson, "An application of the prototype willingness model to drivers' speeding behaviour," European Journal of Social Psychology, vol. 47, no. 6, pp. 735-747, 2017.

[48] C. Preece, A. Watson, S.-A. Kaye, and J. Fleiter, "Understanding the psychological precursors of young drivers' willingness to speed and text while driving," Accident Analysis \& Prevention, vol. 117, pp. 196-204, 2018.

[49] F. X. Gibbons, M. Gerrard, H. Blanton, and D. W. Russell, "Reasoned action and social reaction: willingness and intention as independent predictors of health risk," Journal of Personality and Social Psychology, vol. 74, no. 5, pp. 11641180, 1998.

[50] A. Rivis, P. Sheeran, and C. J. Armitage, "Augmenting the theory of planned behaviour with the prototype/willingness model: predictive validity of actor versus abstainer prototypes for adolescents' health-protective and health-risk intentions," British Journal of Health Psychology, vol. 11, no. 3, pp. 483500, 2006.

[51] M. K. Hyde and K. M. White, "Are organ donation communication decisions reasoned or reactive? A test of the utility of an augmented theory of planned behaviour with the prototype/willingness model," British Journal of Health Psychology, vol. 15, no. 2, pp. 435-452, 2010.

[52] L. T. Hu and P. M. Bentler, "Cutoff criteria for fit indexes in covariance structure analysis: conventional criteria versus new alternatives," Structural Equation Modeling: A Multidisciplinary Journal, vol. 6, no. 1, pp. 1-55, 1999.

[53] B. G. Tabachnick and L. S. Fidell, Using Multivariate Statistics, Pearson, Boston, MA, USA, 2013.

[54] D. Evans and P. Norman, "Understanding pedestrians' road crossing decisions: an application of the theory of planned behaviour," Health Education Research, vol. 13, no. 4, pp. 481-489, 1998

[55] M. A. Elliott and J. A. Thomson, "The social cognitive determinants of offending drivers' speeding behaviour," Accident Analysis \& Prevention, vol. 42, no. 6, pp. 1595-1605, 2010.

[56] S. Demir, B. Demir, and T. Özkan, "When do drivers conform? When do they deviate?" Transportation Research Part F: Traffic Psychology and Behaviour, vol. 54, pp. 299-310, 2018.

[57] R. Zhou, C. Wu, P.-L. Patrick Rau, and W. Zhang, "Young driving learners' intention to use a handheld or hands-free mobile phone when driving," Transportation Research Part F: Traffic Psychology and Behaviour, vol. 12, no. 3, pp. 208-217, 2009.

[58] D. K. Lapsley and P. L. Hill, "Subjective invulnerability, optimism bias and adjustment in emerging adulthood," Journal of Youth and Adolescence, vol. 39, no. 8, pp. 847-857, 2010. 